\title{
The Assessment and Predicting of Land Use Changes to Urban Area Using Multi-Temporal Satellite Imagery and GIS: A Case Study on Zanjan, IRAN (1984-2011)
}

\author{
Mohsen Ahadnejad Reveshty \\ Department of Geography, Faculty of Human Science, Zanjan University, Zanjan, Iran \\ E-mail: ahadnejad@gmail.com \\ Received August 10, 2011; revised September 15, 2011; accepted September 25, 2011
}

\begin{abstract}
Due to inappropriate planning and management, accelerated urban growth and tremendous loss in land, especially cropland, have become a great challenge for sustainable urban development [1]. Detection of such changes may help decision makers and planners to understand the factors in land use and land cover changes in order to take effective and useful measures. Remote sensing and GIS techniques may be used as efficient tools to detect and assess land use changes.In recent years, a considerable land use changes have occurred in the greater Zanjan area. In order to understand the type and rate of changes in this area, Landsat TM images captured in 1984 and 2011 have been selected for comparison.First, geometric correction and contrast stretch are applied. In order to detect and evaluate land use changes, image differencing, principal component analyses and Fuzzy ARTMAP classification method are applied. Finally, the results of land cover classification for three different times are compared to reveal land use changes.Then, combined Cellular Automata with Markov Chain analysis is employed to forecast of human impacts on land use change until 2020 in Zanjan area. The results of the present study disclose that about 44 percents of the total area changed their land use, e.g., changing agricultural land, orchard and bare land to settlements, construction of industrial areas and highways. The crop pattern also changes, such as orchard land to agricultural land and vice versa. The mentioned changes have occurred within last 27 years in Zanjan city and its surrounding area.
\end{abstract}

Keywords: Cellular Automata, Change Detection, Forecast, Fuzzy ARTMAP, Land-Use, Urban Area

\section{Introduction}

Land cover/land use changes are very dynamic in nature and have to be monitored at regular intervals for sustainable environment development. Remote Sensing data is very useful because of its synoptic view, repetitive coverage and real time data acquisition. The digital data in form of satellite imageries, therefore, enable to accurately compute various land cover/land use categories and helps in maintaining the spatial data infrastructure (SDI) which is very essential for monitoring urban expansion and change detections studies [2]. In other words, the remote sensing satellite data in multi-resolution and multispectral means to provide spatial information for land cover/ land use at different levels for various aspects as built-up land, agricultural land, forests, wastelands and water bodies etc. So, the land cover/land use maps prepared using multidate and multispectral data provides different levels of spatial information which are used in change detection studies [3].

In the present research, supervised classification based on Fuzzy Artmap is employed to detect land use changes occurred in the Zanjan area, Iran. For forecasting of land-use change until 2020, both Cellular Automata and Markov Chain were employed.

The study area is located between $36^{\circ} 38^{\prime} 56^{\prime \prime}$ to $36^{\circ} 42^{\prime \prime}$ $22^{\prime \prime} \mathrm{N}$ and $48^{\circ} 25^{\prime} 42^{\prime \prime}$ to $48^{\circ} 33^{\prime} 05^{\prime \prime} \mathrm{E}$. The area covers Zanjan city and its surrounding area with 10,193 hectares. The study area comprises two topographic units' foothill and plain. Zanjan population in 1986 was about 215,458 people and its population has been reached to 349,713 people in 2006, the population growth rate in this period was about 3.93 percent. The main reason to select this area is that considerable land-use changes have occurred due to urban developments, rural developments, and industrial developments in the east, west and south areas, 
and that major changes in the crop pattern are ongoing.

Many researchers have employed satellite imagery for land use mapping as well as change detection. Sunar (1996) has compared the results of five different techniques: band combination, subtraction, band division, principal component analysis and classification, in Ekitally, Turkey [4]. This study revealed that the principal component analysis (PCA) shows better results comparing with classification results. Gupta and Parakash (1998) used a combined method of color composite, band subtraction, band division and supervised classification to prepare a land-use map for change detection in a coalmining district in India [5]. They concluded that the supervised classification gives better results for detecting changes. Ahanejad (2002) used PCA, image differencing and classification methods for change detection in Maragheh region, Iran. He concluded that a crosstab method and a comparison image classification method are very suitable for land use change assessment [6]. Neshat (2002) employed Markov Chain to detect the change of forest areas to urban use in Golestan province, Iran [7].

\section{Material and Methods}

In this paper, Landsat TM images captured in 1984, 1991, 2006 and 2011 are employed for digital image processing. Figure 1 shows Landsat TM image were used in this study. Also Figure 2 shows the flowchart of this study.

Various methods have been employed for classification of satellite imagery. Recently, artificial fuzzy methods are used widely because they show very high accuracy in comparison with the conventional ones like Maximum Likelihood Classification (MLC), Minimum Distance

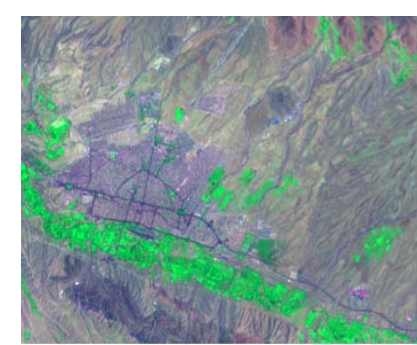

Zanjan Area-Landsat5-1984-02-26

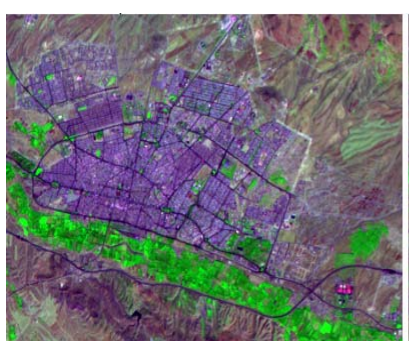

Zanjan Area-Landsat5-2006-09-27

Figure 1. 741 Landsat TM colour composite images.
Classification, and Parallelepiped Classification [8,9].

In this paper, the fuzzy adaptive resonance theory (Fuzzy Artmap) is employed for image classification. First, 741 RGB color composites of Landsat images were prepared. Then, training areas were selected for 6 land use and Land cover classes, which are built-up area, orchards, irrigated agriculture land, dry farming, water, regolith and waste land. These training areas were determined, referring to aerial photographs and GIS thematic maps. To assess the accuracy of classification, topographic maps and aerial photos were employed. Overall accuracy was estimated to be around 96.\% Figures 3 to 6 shows the results of land use classification and Table 1 shows the summary of the classification.

The classification results for the four different times revealed that the land use of the target area has changed about 44\% during the period of 1984-2011. Table 2 shows the estimated land use transitions based on the comparison of the classification results for the 1984 and 2011 images. More than $68 \%$ of the area that belongs to built-up changes to dry farming and waste areas. Dry land farming attains the least changes $25 \%$ in this period (Table 2).

The results also show that built-up area changed from 1418 hectare in 1984 to 4662 hectare in 2011. The increase is mainly due to the needs of settlements in Zanjan City because its population has increased from 215,458 in 1986 to 349,713 in 2006. New suburban areas, such as Sayan, Elahieh, Amir Kabir, GolShahr and Kazemieh, have also developed in the period. Figure 7 shows builtup area growth in case study area.

The Results of Land use changes analysis show that in case study area dry farming and regolith and waste land have most change to built-up area that respectively 2187 and 885 hectares. Also water body and orchards have minimum changes to built-up area that respectively 4 and 58 hectares. Table 3 shows land use transition to built-up area in case study area during 1984-1991, 1991-2006 and 2006-2011.

In totally in Land use and Land cover changes in 1984-2011, Built-up area have maximum changes with 47.04 percent and minimum changes related to water body with 0.01 percent changes. Figures 8-11 shows the areas that have changed to built-up ones in the period of 1984-2011.

One of other analysis in this paper related to land use persistence in the period of 1984-2011 in case study area. It means that how much of land use and land cover and what areas have persistence in during of study periods and has not changes. According to analysis in this case study area about 4329 hectares of land use and land cover have not any changes and 5864 hectare of land use and land cover has been changed in the study period 1984-2011. 


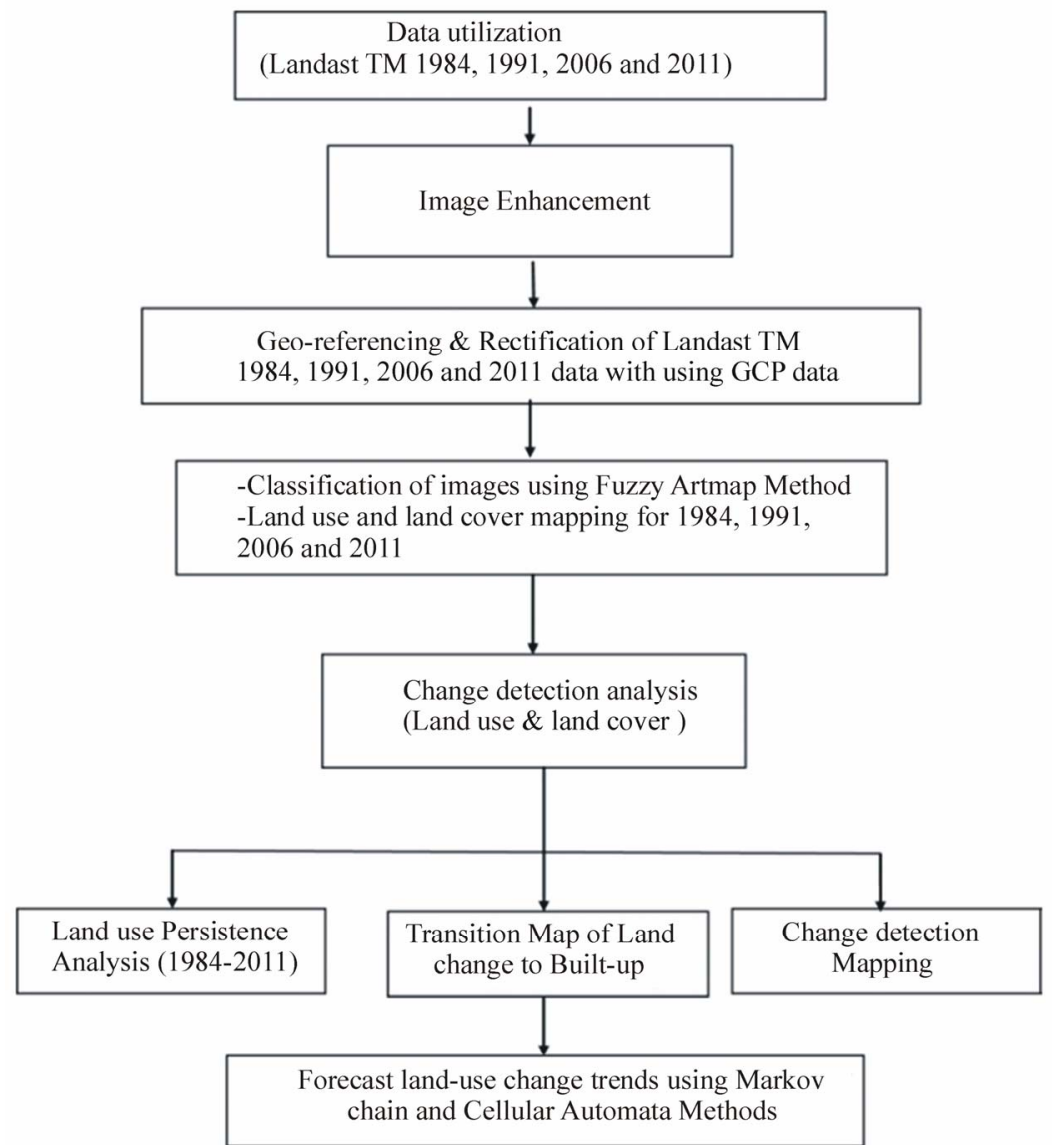

Figure 2. Flow chart showing the major steps research.

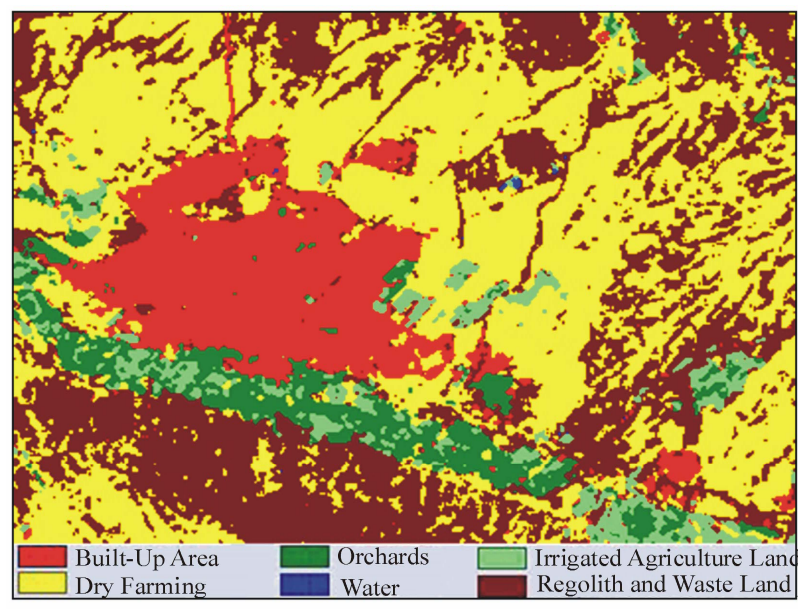

Figure 3. Result of land use classification for Zanjan, Iran using Landsat TM image captured in 1984.

Table 4 and Figure 12 shows that spatial distribution map of land use and land cover persistence in the period of 1984-2011.

In between land use Dry Farming with 2167 hectare has most persistence in comparing with another land use and

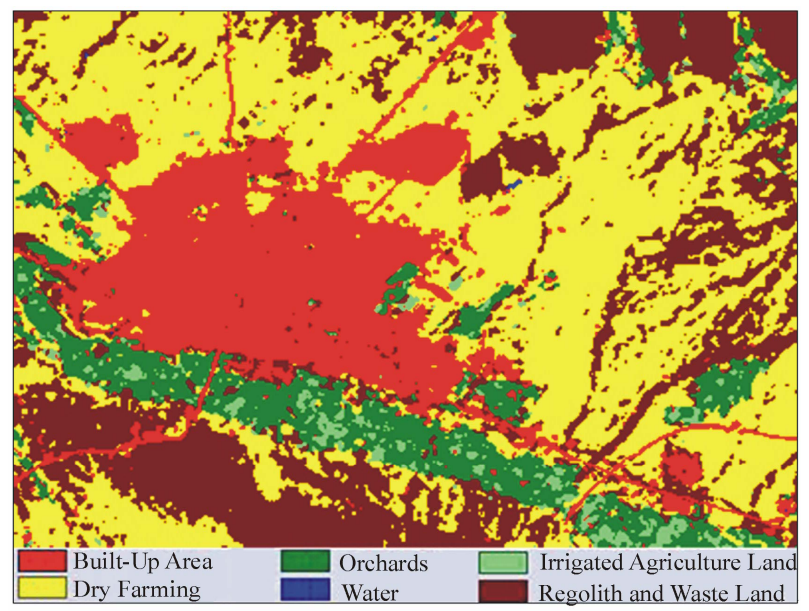

Figure 4. Result of land use classification using Landsat ETM + image captured in 1991.

Irrigated Agriculture Land with 58 hectare has lowest persistence in case study area. Also dry farming with 2375 hectare has maximum changes and orchards with 198 hectare have minimum changes in Zanjan area between 1984 and 2011. 


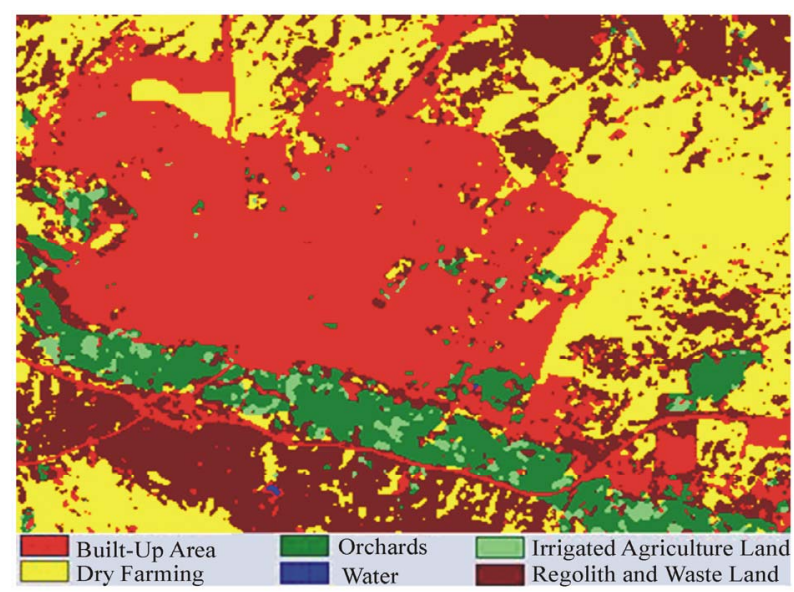

Figure 5. Result of land use classification using Landsat ETM + image captured in 2006.

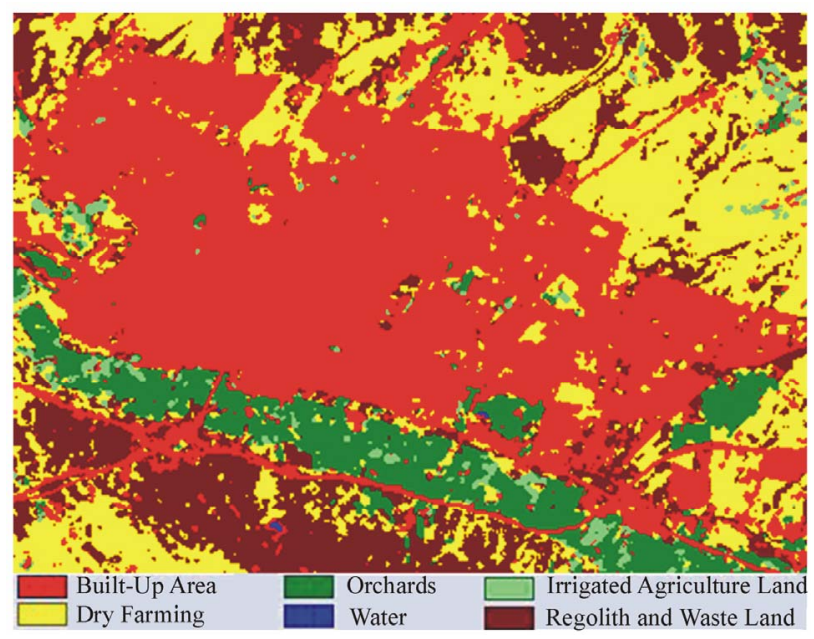

Figure 6. Result of land use classification using Landsat ETM + image captured in 2011.

Table 1. Summary of land use change to urban area in study area (Hectares).

\begin{tabular}{cccccc}
\hline Class & Landuse Type & $\mathbf{1 9 8 4}$ & $\mathbf{1 9 9 1}$ & $\mathbf{2 0 0 6}$ & $\mathbf{2 0 1 1}$ \\
\hline 1 & Built-Up Area & 1418 & 2068 & 3669 & 4662 \\
2 & Dry Farming & 4542 & 4453 & 3016 & 2547 \\
3 & Orchards & 651 & 973 & 877 & 907 \\
4 & Water & 5 & 4 & 3 & 3 \\
5 & $\begin{array}{c}\text { Irrigated Agri- } \\
\text { culture }\end{array}$ & 449 & 210 & 174 & 191 \\
6 & $\begin{array}{c}\text { Regolith and } \\
\text { Waste }\end{array}$ & 3128 & 2485 & 2453 & 1883 \\
& Total-Hectare & 10,193 & 10,193 & 10,193 & 10,193 \\
\hline
\end{tabular}

\section{Discussion}

The other object of this paper is to predict the trend of land use changes in the future. Many methods can be applied to predict the trend. In this paper, two methods are used.
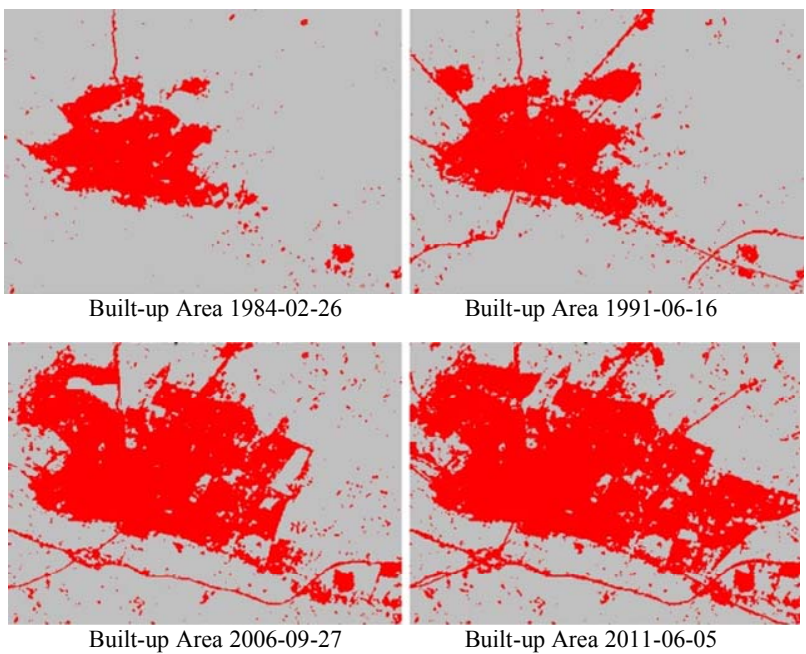

Figure 7. Built-up area growth at during 1984-2011 in case study area.

The first method is Markov chain method analyses a pair of land cover images and outputs a transition probability matrix, a transition area matrix, and a set of conditional probability images. The transition probability matrix shows the probability that one land-use class will change to the others. The transition area matrix tells the number of pixels that are expected to change from one class to the others over the specified period [10].

The conditional probability images illustrate the probability that each land cover type would be found after a specific time passes These images are calculated as projections from the two input land cover images [11,12]. The output conditional probability images can be used as direct input for specification of the prior probabilities in Maximum Likelihood Classification of remotely sensed imagery )such as with the MAXLIKE and BAYCLASS modules.(A raster group file is also created listing all the conditional probability images $[12,13])$.

The second method is Combination of Cellular Automata and Markov Chain. To know the changes that have occurred in the past may help to predict future changes. Combination of Cellular Automata and Markov Chain is often employed to predict land cover change estimation.

In this study, a series of image processing was performed to predict the trend of land use change in 2020 (Table 5). The result shows that the probability to change to Built-up area is highest. Figure $\mathbf{1 3}$ shows the probability that the area will be converted to Build-up area in 2020.

In order to predict the trends of land use changes, first 1984 and 2011 land use map were analyzed with Markov Chain. Then, combined method of Cellular Automata and Markov Chain was used for forecasting land use change in 2020. According to the results (Figure 14 and Table 6), 


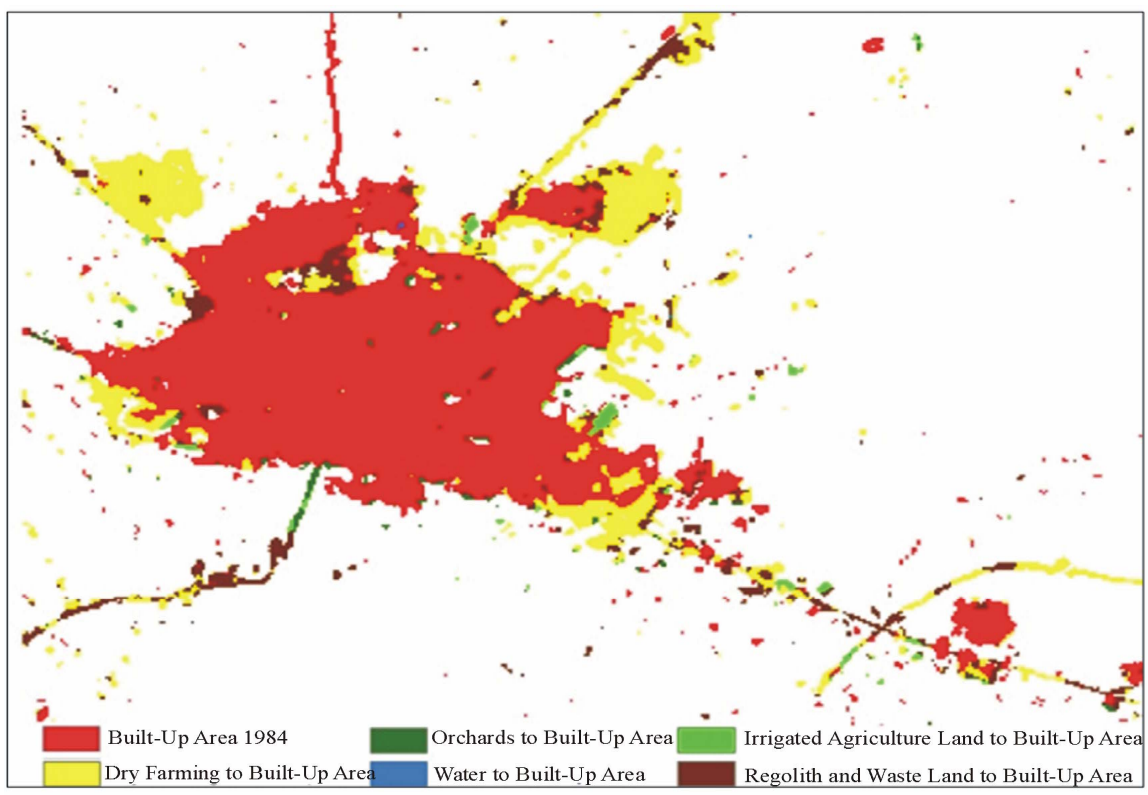

Figure 8. The areas that have changed to built-up ones in the period of 1984-1991.

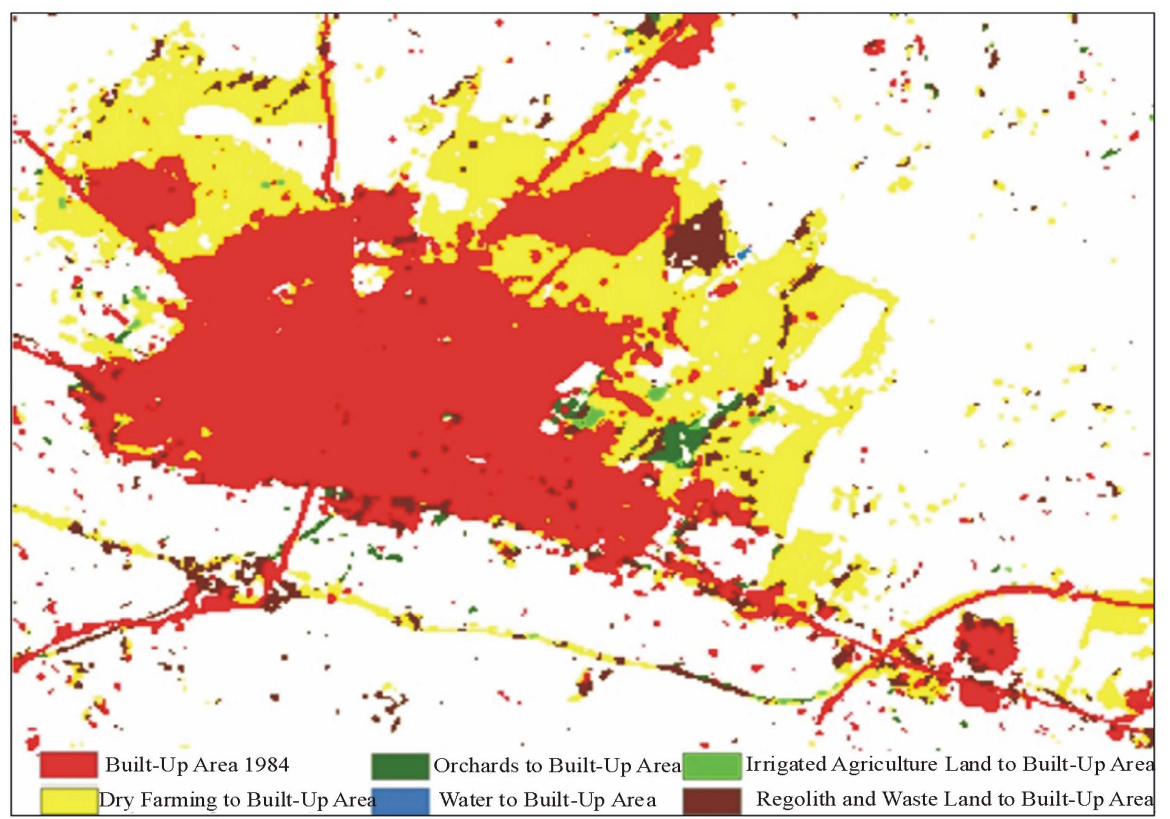

Figure 9. The areas that have changed to built-up in the period of 1991-2006.

Table 2. Estimated land use transitions in Zanjan area between 1984 and 2011 (Hectare).

\begin{tabular}{ccccccccc}
\hline Class & 1 & 2 & 3 & 4 & 5 & 6 & Total & Change \\
\hline 1 & 1418 & 0 & 0 & 0 & 0 & 0 & 1418 & 14 \\
2 & 2187 & 2167 & 97 & 0 & 53 & 39 & 4542 & 45 \\
3 & 58 & 41 & 454 & 0 & 53 & 45 & 651 & 6 \\
4 & 4 & 0 & 0 & 0 & 0 & 1 & 5 & 0 \\
5 & 111 & 30 & 220 & 0 & 58 & 30 & 449 & 4 \\
6 & 885 & 310 & 136 & 2 & 28 & 1768 & 3128 & 31 \\
Total & 4662 & 2547 & 907 & 3 & 191 & 1883 & 10,193 & 100 \\
Change & 46 & 25 & 9 & 0 & 2 & 18 & & \\
\hline
\end{tabular}

(Row related to 1984 land use and Column related to 2011 land use) 
Table 3. Summary of image classification performed in study area (Hectares).

\begin{tabular}{cccccc}
\hline Class & Land use Type & $1984-1991$ & $1991-2006$ & $2006-2011$ & Total \\
\hline 2 & Dry Farming & 405 & 1161 & 621 & 2187 \\
3 & Orchards & 17 & 20 & 21 & 58 \\
4 & Water & 1 & 2 & 1 & 4 \\
5 & Irrigated Agriculture & 38 & 68 & 5 & 111 \\
6 & Regolith and Waste & 189 & 350 & 345 & 885 \\
& Total(H) & 650 & 1601 & 993 & 3244 \\
\hline
\end{tabular}

Table 4. Estimated land use persistence and changes in Zanjan Area during 1984 and 2011.

\begin{tabular}{cccc}
\hline ID & Type & Persistence & Changes \\
\hline 1 & Built-Up Area & 1418 & 0.00 \\
2 & Dry Farming & 2167 & 2375 \\
3 & Orchards & 454 & 198 \\
5 & Irrigated Agriculture Land & 58 & 390 \\
6 & Regolith and Waste Land & 1768 & 1361 \\
& Total & 5864 & 4329 \\
\hline
\end{tabular}

Table 5. The probability of land use changes based on Markov Chain in the period of 2011-2020.

\begin{tabular}{ccccccc}
\hline Class & 1 & 2 & 3 & 4 & 5 & 6 \\
\hline 1 & 1.000 & 0.000 & 0.000 & 0.000 & 0.000 & 0.000 \\
2 & 0.258 & 0.713 & 0.010 & 0.000 & 0.014 & 0.005 \\
3 & 0.002 & 0.035 & 0.834 & 0.000 & 0.089 & 0.041 \\
4 & 0.762 & 0.000 & 0.000 & 0.000 & 0.000 & 0.238 \\
5 & 0.153 & 0.051 & 0.540 & 0.000 & 0.208 & 0.048 \\
6 & 0.105 & 0.079 & 0.023 & 0.001 & 0.006 & 0.785 \\
\hline
\end{tabular}

(Row related to 2011 and Column related to 2020)

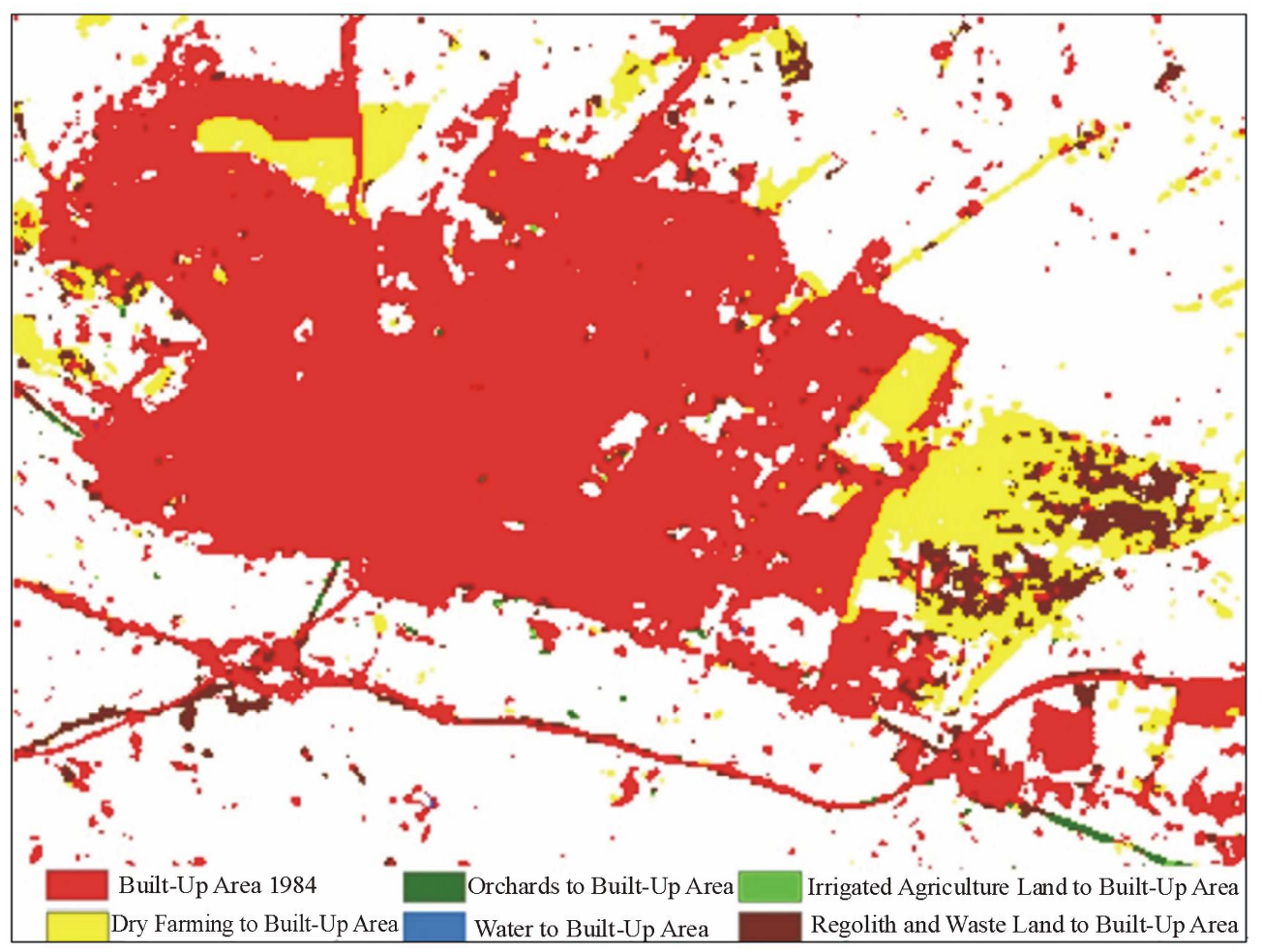

Figure 10. The areas that have changed to built-up in the period of 2006-2011.

built-up areas increase from 4662 hectare in 2011 to 5550 hectares in 2020 and the probability change dry farming to built-up area is highest in comparing with other land use and land cover types. 


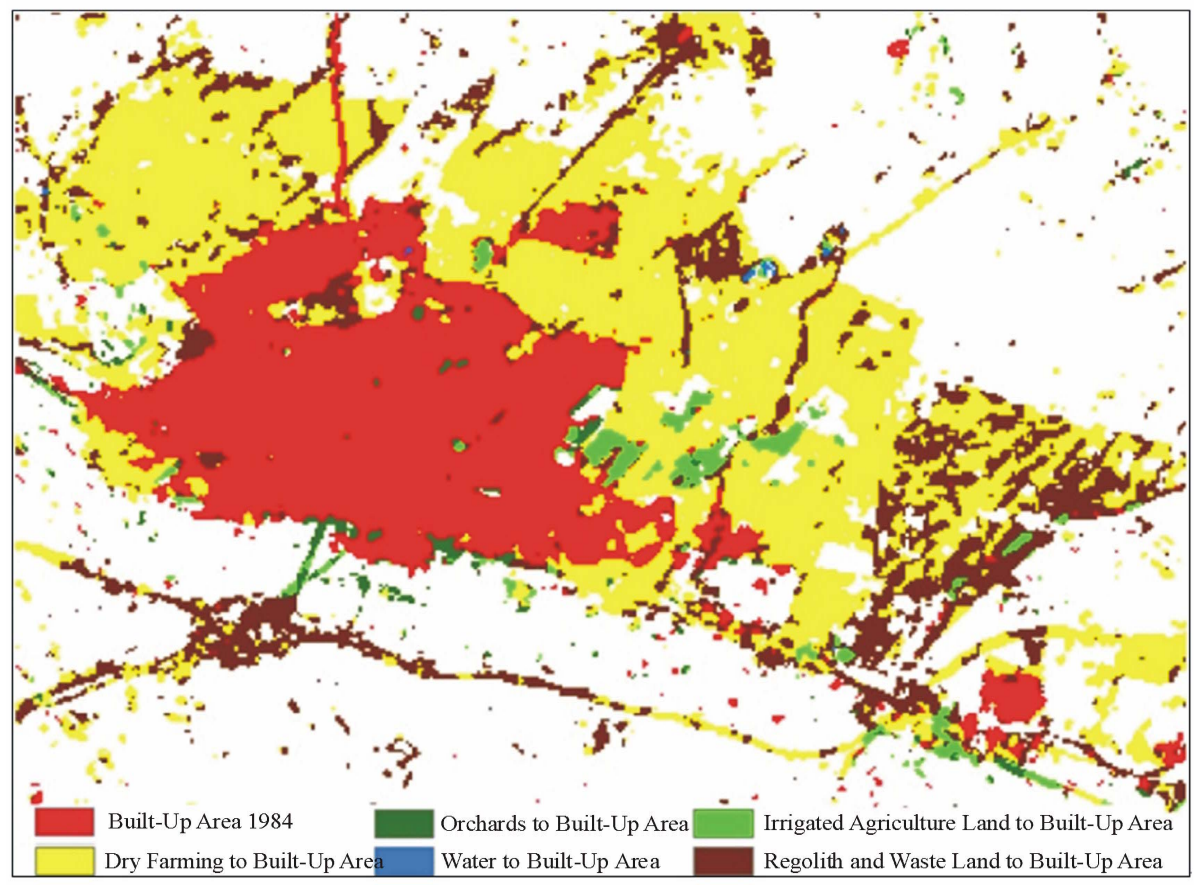

Figure 11. The areas that have changed to built-up in the period of 1984-2011.

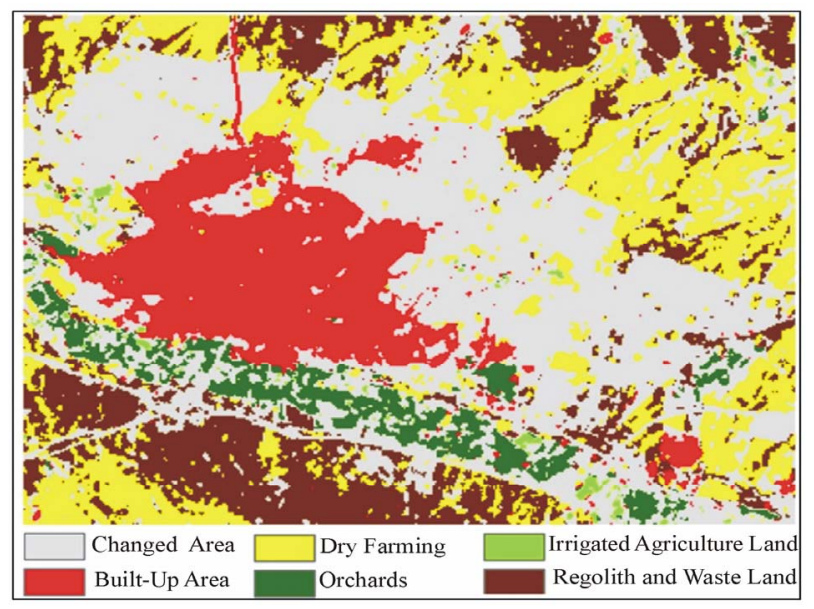

Figure 12. The areas have that Land use persistence between 1984-2011.

\section{Conclusions}

In this paper, using Landsat Satellite images in 1984 and 2011, land use changes in Zanjan city area, Iran were evaluated. For classification of the images, Fuzzy Artmap classification method was applied, which has very high confidence comparing with other classification methods. In addition, combined Cellular Automata with Markov Chain method was employed to forecast human impacts on land use change until 2020 for the study area.

The results revealed that the land use change has occurred for the area of about 4329 hectares in the period

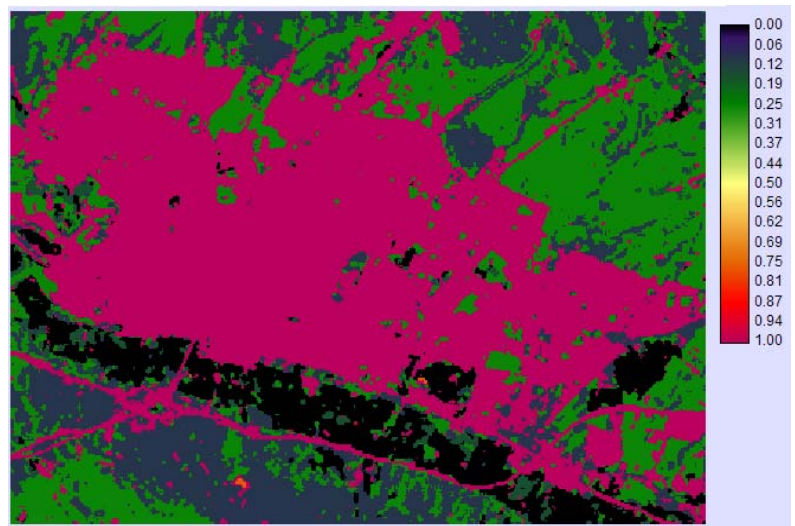

Figure 13. The probability to remain/change to built-up areas by 2020 obtained by Markov Chain.

Table 6. The result of prediction of land use in 2020 by the combination of Cellular Automata and Markov Chain.

\begin{tabular}{cccccccc}
\hline Land use & $\mathbf{1}$ & $\mathbf{2}$ & $\mathbf{3}$ & $\mathbf{4}$ & $\mathbf{5}$ & $\mathbf{6}$ & Total \\
\hline 1 & 4662 & 0 & 0 & 0 & 0 & 0 & 4662 \\
2 & 659 & 1869 & 0 & 0 & 19 & 0 & 2546 \\
3 & 0 & 2 & 897 & 0 & 8 & 0 & 907 \\
4 & 2 & 0 & 0 & 1 & 0 & 0 & 3 \\
5 & 29 & 0.3 & 25 & 0 & 137 & 0 & 191 \\
6 & 198 & 137 & 6 & 1 & 1.9 & 1538 & 1882 \\
Total & 5550 & 2008 & 929 & 2 & 166 & 1538 & 10193 \\
\hline
\end{tabular}

(Row related to 2011 land use and Column related to 2020 land use)

1984-2011. These changes due to developments of settlements on orchards and agriculture lands, which occurred mostly in the urban fringe of Zanjan city, are recognized as highly impacted areas from the environmental 


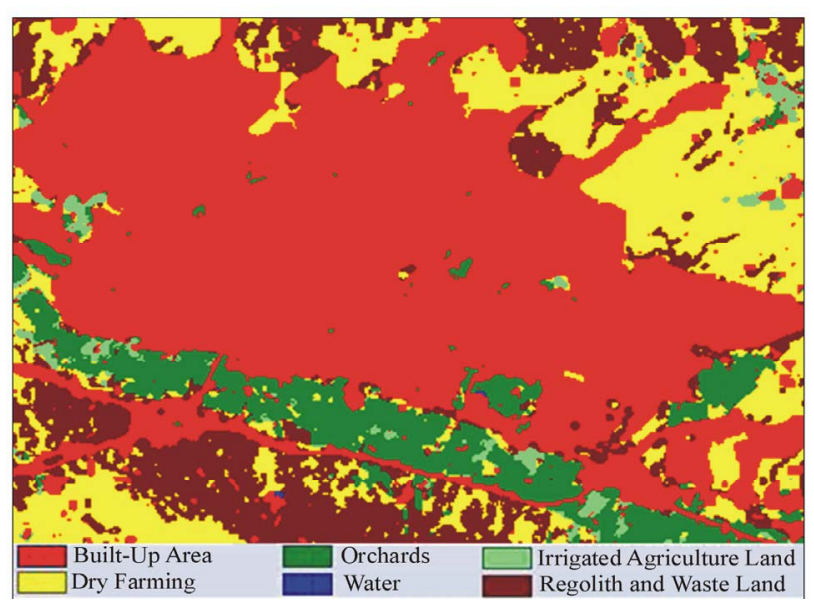

Figure 14. Predicted result of land-use change in 2020 by the combination of Cellular Automata and Markov Chain.

point of view.

According to Cellular Automata and Markov Chain Forecasting model, built-up areas will increase from 4662 hectares in 2011 to 5550.4 hectares in 2020. The continuation of such a trend may endanger the surrounding land as well as the agricultural lands and orchards in the area. Hence, it is recommended to protect these critical areas.

The results of this study also revealed that dry farming land around major towns and settlements are recognized as critical regions in terms of land use changes, and special protection measures are needed to be taken. In case of improper planning, these regions will be changed to settlements in a very short time, which is totally in contradiction to sustainable development.

\section{References}

[1] J.-S. Deng, K. Wang, J. Li and Y.-H. Deng, "Urban Land Use Change Detection Using Multisensory Satellite Images," Pedosphere, Vol. 19, No. 1, 2008, pp. 96-103. doi:10.1016/S1002-0160(08)60088-0

[2] C. P. Lo, "Land Use Mapping of Hong Kong From Landsat Images: An Evaluation," International Journal of Remote Sensing, Vol. 2, No. 3, 1981, pp. 231-251. doi:10.1080/01431168108948359
[3] P. A. Burrough, "Principles of Geographic Information System for Land Resource Assessment," Clarendon Press, Oxford, 1986.

[4] F. Sunar, "An Analysis of Changes in a Multi-Data Set; a Case Study in the Ikitelli Area Istanbul Turkey," International Journal of Remote Sensing, Vol. 19, No. 2, 1998, pp. 225-235. doi:10.1080/014311698216215

[5] A. Prakash and R. Gupta, "Land Use Mapping and Change Detection in a Coal Mining Area, a Case Study in the Jharia coalfield, India," International Journal of Remote Sensing, Vol. 19, No. 3, 1998, pp. 391-410. doi:10.1080/014311698216053

[6] M. Ahadnejad, "Environmental Land Use Chang Detection and Assessment Using with Multi-Temporal Satellite Imagery," Mapasia, Bangkok, 2002.

[7] A. Neshat, "Analysis and Evaluation Land Use and Land-Cover Changes Using Remote Sensing Data and Geographic Information Systems in Golestan Province," Master's Thesis, Tarbiat Modaress University, Tehran, 2002.

[8] T.-H. Tong Hou and M.-D. Pern, "New Shape Classifier by Using Image Projection and a Neural Network," International Journal of Pattern Recognition and Artificial Intelligence, Vol. 14, No. 2, 2000, pp. 225-242.

[9] D. Muchoney and J. Williamson, "A Gaussian Adaptive Resonance Theory Neural Network Classification Algorithm Applied to Supervised Land Cover Mapping Using Multi Temporal vegetation Index Data," IEEE Transactions on Geoscience and Remote Sensing, Vol. 39, No. 9, 2001, pp. 1969-1977. doi:10.1109/36.951087

[10] J. R. Eastman, "IDRISI Andes Tutorial," Clark Labs, Clark University, Worcester, 2006.

[11] R. G. Pontius Jr and H. Chen, "Land Change Modeling with GEOMOD," Clark University, Worcester, 2008.

[12] G. A. Carpenter, S. Grossberg and J. H. Reynolds, "ARTMAP: Supervised Real-Time Learning and Classification of Non Stationary Data by a Self-Organizing," Neural Network, Vol. 4, No. 5, 1991, pp. 565-588. doi:10.1016/0893-6080(91)90012-T

[13] G. A. Carpenter, "Neural Network Models for Pattern Recognition and Associative Memory," Neural Networks, Vol. 2, No. 4, 1989, pp. 243-257. doi:10.1016/0893-6080(89)90035-X 